\title{
LOW-PRESSURE DIFFUSION BONDING OF SAE 316 STAINLESS STEEL BY INSERTING A SUPERPLASTIC INTERLAYER
}

\author{
M.S. Yeh and T.H. Chuang \\ Institute of Materials Science and Engineering, \\ National Taiwan University, Taipei, Taiwan, R. O. C. \\ (Received March 13, 1995) \\ (Revised June 8, 1995)
}

\section{Introduction}

Diffusion bonding is a solid-state joining technique in which two similar or dissimilar materials are brought together under pressure at a temperature below the melting point of the materials. According to the mechanisms proposed by King et. al. (1) and Tanuma et. al. (2), the diffusion bonding process consists of three stages : during the first stage, the contact area increases by localized deformation and creep. In the second step, diffusion takes place at the contact area and eliminates the voids at the original grain interface. Finally, the grain boundaries on the interface migrate and growth occurs. However, Parks (3) thought that the deformed metal will recrystallize in the bonding process so that the mechanism of diffusion bonding is recrystallization.

In order to get a sound joint, diffusion bonding requires that the bonding surfaces be as smooth as possible to provide a greater contact area, which increases the atomic diffusion paths. Since no surface is absolutely flat, the workpiece to be bonded should be plastically deformed locally through a applied stress. If the flow stress of the material is high, the applied stress will not be enough to cause local plastic deformation of this material. Then many voids and pores will remain at the interface after diffusion bonding. In this case, a good joint cannot be achieved and the bonding quality will be degraded. Although higher pressure or longer heating time could improve the bonding effect for these high strength materials $(4,5)$, the manufacturing cost will be increased.

For a material with lower flow stress, the applied pressure needed to provide a initimate contact surface will also be low. Another advantage in this case is that even if the workpieces possess a rougher surface it can be effectively bonded. A superplastic alloy is a typical example of such a material with lower flow stress. Furthermore, a superplastic alloy possesses very fine grains and thus more grain boundary diffusion paths will be present, which provides another beneficial effect for diffusion bonding.

However, most commercial technical alloys do not have superplastic characteristics. In order to use the above advantages of lower flow stress and more diffusion paths only existing for superplastic materials, an innovative process has been proposed. By inserting a superplastic interlayer with diffusion bonding compatibility in between the workpieces to be bonded, a better bond may be obtained. In the present study, a SAE 316 stainless steel was diffusion bonded by this method. A SuperDux 65 stainless steel plate was employed as its superplastic interlayer. 
TABLE 1

Nominal Chemical Composition of SAE 316 and SuperDux 65 Stainless Steels (wt\%)

\begin{tabular}{lllllllllllll}
\hline Alloy & $\mathrm{Fe}$ & $\mathrm{Ni}$ & $\mathrm{Cr}$ & $\mathrm{Mo}$ & $\mathrm{C}$ & $\mathrm{Si}$ & $\mathrm{Mn}$ & $\mathrm{P}$ & $\mathrm{S}$ & $\mathrm{Cu}$ & $\mathrm{Al}$ & $\mathrm{N}$ \\
\hline SAE 316 & $\mathrm{Bal}$ & 12.0 & 17.0 & 2.5 & 0.05 & 1.0 & 2.0 & 0.045 & 0.03 & - & - & - \\
$\begin{array}{l}\text { SuperDux } \\
65\end{array}$ & $\mathrm{Bal}$ & 5.9 & 23.8 & 1.5 & 0.03 & 0.7 & 0.7 & 0.035 & 0.002 & 1.1 & 0.05 & 0.14 \\
\hline
\end{tabular}

\section{Experimental Procedure}

The material chosen for study was a commercial SAE 316 stainless steel rod (20 mm diameter, nonsuperplastic alloy). In preparation for diffusion bonding, $58 \mathrm{~mm}$ length specimens were cut from the rod. Two types of faying surface were obtained by grinding with 80 grit SiC paper or polishing with $0.3 \mu \mathrm{m}$ alumina powder. The SuperDux 65 superplastic duplex stainless steel, which has a two-phase ferritic-austenitic microstructure and fine grains was manufactured by Nippon Yakin Kogy Co. Ltd, Japan. Interlayers of SuperDux 65 with diameter of $20 \mathrm{~mm}$ were cut from a 1-mm-thick SuperDux 65 plate. The nominal chemical compositions of SAE 316 and SuperDux 65 stainless steels are given in Table 1. For diffusion bonding, an interlayer of SuperDux 65 superplastic duplex stainless steel was inserted in between two non-superplastic SAE 316 stainless steel bars. The bonding assembly is shown in Fig.1 . For comparison, two pieces of SAE 316 stainless steel bars were also directly diffusion bonded without a superplastic interlayer. Before bonding, each assembly was ultrasonically cleaned in acetone for 5 mins. The diffusion bonding tests were carried out in a hot vacuum press, under a vacuum of $10^{-4}$ torr at $1300 \mathrm{~K}$ for 30 mins under pressures of $4.2 \mathrm{MPa}$ and $7 \mathrm{MPa}$. After bonding, the tensile specimens according to DIN 50125 were machined to the configuration in Fig.2. The bonding interfaces were observed by optical microscopy $(\mathrm{OM})$ and scanning electron microscopy (SEM). Furthermore, the bonding strength and the elongation were measured to evaluate the bonding effect.
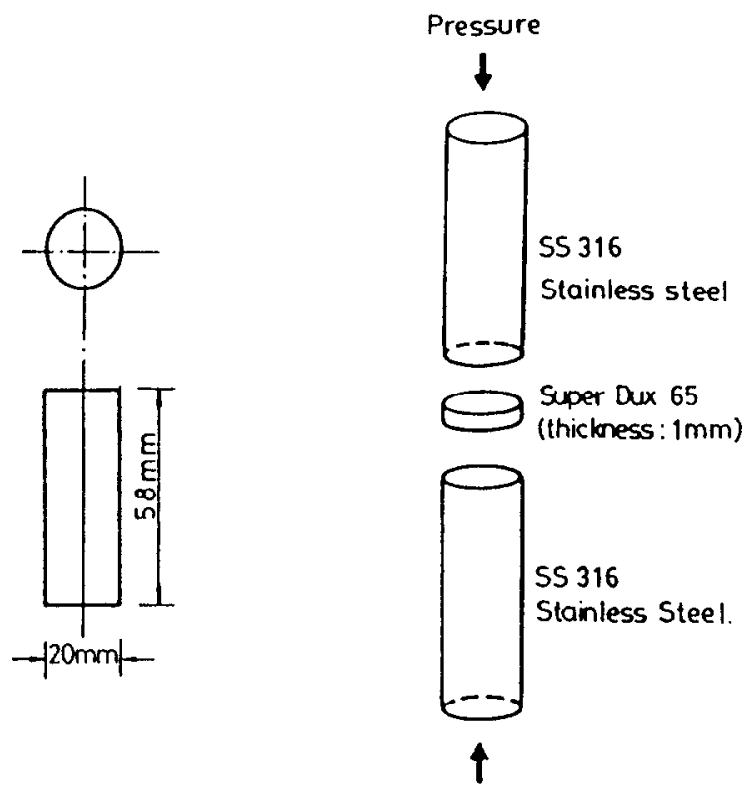

Figure 1. The dimension and joint configuration for tensile specimens assembly. 


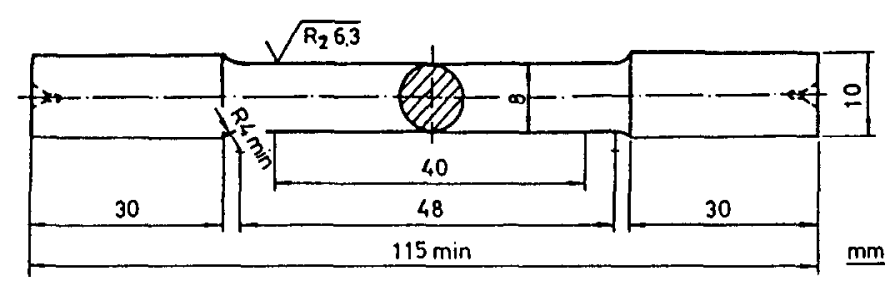

Figure 2. Joint tensile specimen (DIN 50125-A8×40).

\section{Results and Discussion}

The tensile properties of the SAE 316 stainless steel bars before and after diffusion bonding were measured and summarized in Table 2. Due to the heat treatment effect during diffusion bonding a base material of SAE 316 stainless steel was annealed at $1300 \mathrm{~K}$ for $30 \mathrm{mins}$ and tested for comparison. Its tensile property is also shown in Table 2.

Using the conventional method, the surfaces of the two SAE 316 stainless steel rods to be bonded were ground and then polished with $0.3 \mu \mathrm{m}$ alumina powder. Diffusion bonding was conducted under a pressure of $7 \mathrm{MPa}$ at $1300 \mathrm{~K}$ for $30 \mathrm{mins}$. The ultimate tensile strength was $629 \mathrm{Mpa}$ and the elongation was $52.5 \%$. The tensile specimens broke at the plane of the joint. When the roughness of the surfaces to be bonded was increased, the tensile strength decreased drastically to $238 \mathrm{MPa}$ and the elongation was very small $(<2 \%)$. Fig. 3 shows the bonding interface of the sample with its surface ground with 80 grit SiC paper before diffusion bonding. Voids were found at the bondline, which indicates that the joint is not acceptable. When the surfaces to be bonded were further polished with $0.3 \mu \mathrm{m}$ alumina powder, no voids were observed under optical microscopy, but microvoids were still found at the bonding interface using SEM as shown in (Fig.4). The ductile dimples which are observed at some parts of the fracture surface indicates a sound bonding in these regions. However, the grinding marks can still be observed on fracture surface which means that the sample was not completely bonded (Fig.5).

When a thin plate of $1 \mathrm{~mm}$ thick of SuperDux 65 superplastic duplex stainless steel was then inserted in between two non-superplastic SAE 316 stainless steel bars, it can be seen that regardless of the roughness

TABLE 2

Tensile Properties of Diffusion Bonded SAE 316 Stainless Steel at 1300K for 30 Min

\begin{tabular}{|c|c|c|c|c|c|}
\hline Surface finish & Interlayer & $\begin{array}{l}\text { Bonding } \\
\text { pressure (MPa) }\end{array}$ & $\begin{array}{l}\text { Tensile } \\
\text { strength (MPa) }\end{array}$ & Elongation (\%) & $\begin{array}{l}\text { Location of } \\
\text { fracture }\end{array}$ \\
\hline Base material & & & 634 & 70.0 & \\
\hline Anneal at $1300 \mathrm{~K}$ & & & 626 & 72.5 & \\
\hline 80 grit SiC paper & & 7 & 238 & $<2$ & bond plane \\
\hline $\begin{array}{l}0.3 \mu \mathrm{m} \mathrm{Al}_{2} \mathrm{O}_{3} \\
\text { polished }\end{array}$ & & 7 & 629 & 52.5 & bond plane \\
\hline 80 grit $\mathrm{SiC}$ paper & Dux65 & 7 & 636 & 70.0 & base material \\
\hline $\begin{array}{l}0.3 \mu \mathrm{m} \mathrm{Al}_{2} \mathrm{O}_{3} \\
\text { polished }\end{array}$ & Dux65 & 7 & 633 & 75.0 & base material \\
\hline $\begin{array}{l}0.3 \mu \mathrm{m} \mathrm{Al}_{2} \mathrm{O}_{3} \\
\text { polished }\end{array}$ & Dux65 & 4.2 & 632 & 72.5 & base material \\
\hline
\end{tabular}

*Dux 65: SuperDux 65 interlayer 


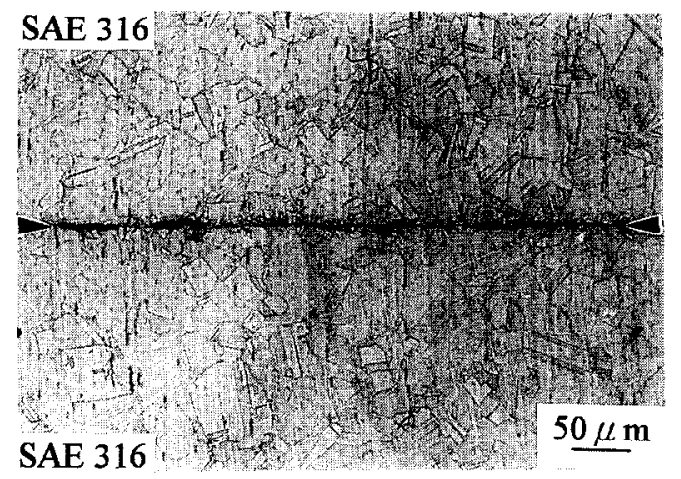

Figure 3. The bonding interfaces of non-superplastic SAE 316 stainless steel bars subjected to $7 \mathrm{MPa}$ at $1300 \mathrm{~K}$ for 30 mins. Surface to be bonded was ground with 80 grit $\mathrm{SiC}$ paper.

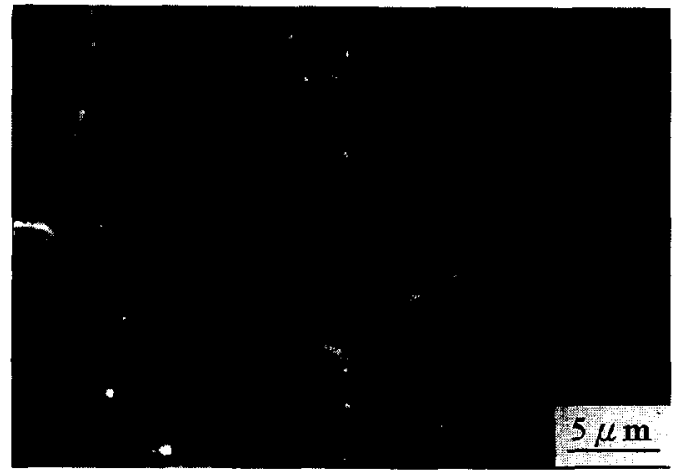

Figure 4. SEM micrograph bonding interfaces of the nonsuperplastic SAE 316 stainless steel bar subjected to $7 \mathrm{MPa}$ at $1300 \mathrm{~K}$ for 30 mins. The surface to be bonded was polished with $0.3 \mu \mathrm{m} \mathrm{Al}_{2} \mathrm{O}_{3}$.

of the surfaces to be bonded, the parent metal strength (634MPa) and elongation (70.0\%) were achieved with the same bonding conditions. The tensile specimens failed in the base metal, i.e. the joint is stronger than the base metal. Furthermore, a bamboo-like shape appeared in the specimen (Fig.6) due to the fact that the SuperDux 65 has a much higher strength than the SAE 316 stainless steel. For the specimen with its surface only ground with 80 grit $\mathrm{SiC}$ paper, Fig.7 shows that the scratches of the surface to be bonded were filled with superplastic SuperDux 65 and no voids were observed at the bonding interface, so a good bond joint was of achieved. When the surface to be bonded was polished with $0.3 \mu \mathrm{m}$ alumina powder, a flatter surface was obtained. In this case, EPMA shows that some parts of the interface migrated away from the original position with $\mathrm{Cr}$ increasing and $\mathrm{Ni}$ decreasing in this region (Fig.8).

Theoretically, two ideal atomically flat and clean surfaces can be bond by interatomic forces. Thus, the pressure applied during diffussion bonding is not necessary (6). In fact, the bonding surfaces are still rough because of the methods used for surface preparation in microscopy. The pressure applied during the process of diffussion bonding causes microscopic plastic deformation at the bonding surface of the workpieces to be bonded. In this way, the bonding surface to be bonded will intimately contact and increase the atomic diffusion paths. The pressure applied also affects the "grain boundary diffusion", "volume diffusion" and "grain

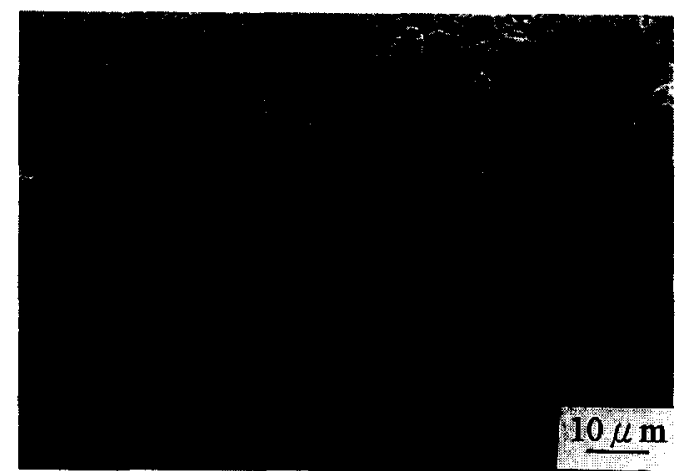

Figure 5. SEM micrograph cross section of the fracture surface of non-superplastic SAE 316 stainless steel bars subjected to $7 \mathrm{MPa}$ at $1300 \mathrm{~K}$ for 30 mins. The surface to be bonded was ground with 80 grit $\mathrm{SiC}$ paper.

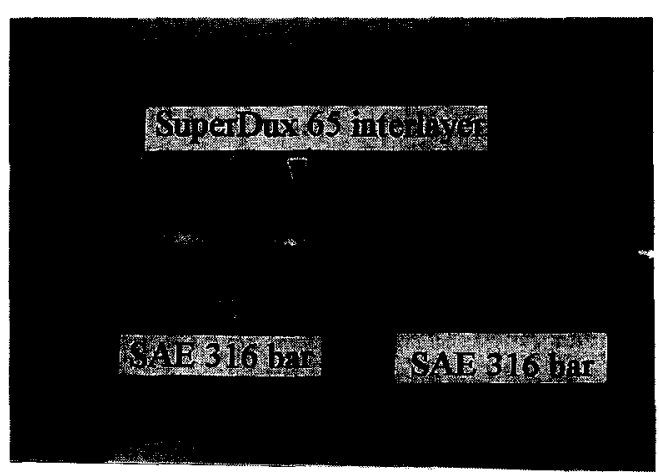

Figure 6. When a superplastic SuperDux 65 plate inserted between the non-superplastic SAE 316 stainless steel bars, fractured tensile specimen showed the bamboo shape. 


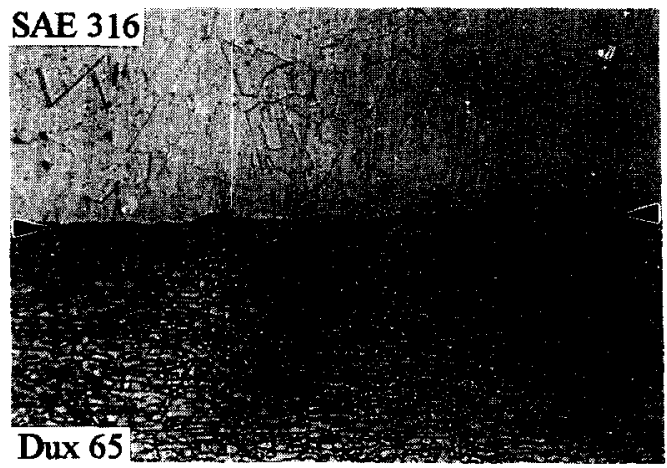

Figure 7. The bonding interfaces of superplastic SuperDux 65 plate inserted between the non-superplastic SAE 316 stainless steel bars subjected to $7 \mathrm{MPa}$ at $1300 \mathrm{~K}$ for $30 \mathrm{mins}$. Surface to be bonded was ground with 80 grit $\mathrm{SiC}$ paper.

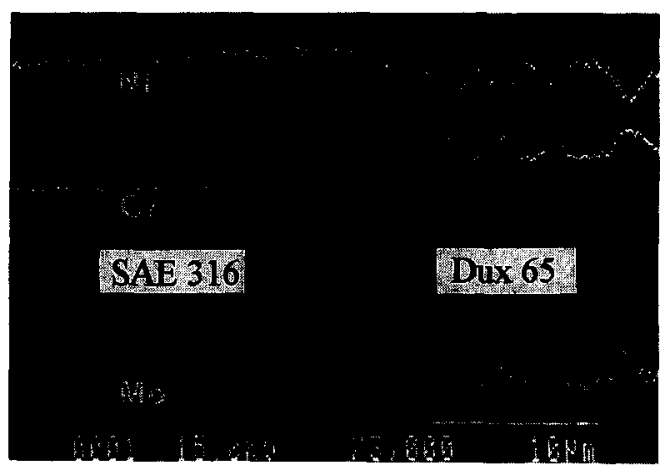

Figure 8. Distribution curves of the intensity of various elements analyzed across the bonding interface of the superplastic SuperDux 65 plate inserted between the nonsuperplastic SAE 316 stainless steel bars subjected to 7MPa at $1300 \mathrm{~K}$ for 30 mins by EPMA. The surface to be bonded was polished with $0.3 \mu \mathrm{m} \mathrm{Al} 2 \mathrm{O}$.

boundary migration" occurring at the bonding interface of workpieces. However, these influences are limited compared with the effect of plastic deformation. Thus, the main role that applied pressure plays during the bonding process is to produce microscopic plastic deform-ation on the bonding surfaces.

When the materials to be diffusion bonded possess a rough surface, larger pressure is necessary to produce microplastic deformation at the bonding surface so as to increase the contact areas and attain the effect of diffusion bonding. Unfortunately, if the workpieces to be bonded have a complex or irregular shape, it is very difficult to employ high pressure.

Superplastic materials can be deformed under low flow stress due to grain boundary sliding. Moreover, superplastic materials have equi-axial and fine granular superplastic structure, which increases the atomic diffusion paths. Therefore, when a thin plate of SuperDux 65 is inserted between two SAE 316 stainless steel bars, the diffusion bonding process becomes easier.

\section{Conclusion}

The non-superplastic SAE 316 stainless steel bars can not be satisfactorily bonded under $7 \mathrm{MPa}$ at $1300 \mathrm{~K}$ for 30 mins even with a polished bonding surface. The ultimate tensile strength was $629 \mathrm{Mpa}$ and the elongation was $52.5 \%$. When the roughness of the surfaces to be bonded was increased, the tensile strength was only $238 \mathrm{MPa}$ and the elongation was very small $(<2 \%)$. When a superplastic SuperDux 65 interlayer was inserted in between two SAE 316 stainless steel bars under the same bonding conditions, regardless of the roughness of the surfaces to be bonded, the parent metal strength $(634 \mathrm{MPa})$ and elongation $(70.0 \%)$ were achieved.

\section{References}

1. W.H. King and W.A. Owczarski, Weld. Res. Suppl., Vol. 47, 444s (1968)

2. K. Tanuma and T. Hashimoto, Trans. NRIM, Vol.12, 141 (1970)

3. John M. Parks, Weld. Res. Suppl., Vol. 32, 209s (1953)

4. G. Garmong N.E. Paton and A.S. Argon, Metall. Trans., Vol. 6A,1269 (1975)

5. A. Wisbey and P.G. Partridge, Mat. Sci. \& Tech. Vol.9, 441 (1993)

6. T. Suga, Y. Takahashi, II. Takagi and S. Sacre, in: Proc.4th Int. Conf. Joining Ceramics, Glass and Metal, Konigswinter, Germany, 1993, «d. H. Krappitz and H.A. Scheeffev, p. 295 